Heath, S. B. (1983). Ways with words: Language, life and work in communities and schools. Cambridge: Cambridge University Press.

Holliday, A. (1994). Appropriate methodology and social context. Cambridge: Cambridge University Press.

Kramsch, C. (1993). Context and culture in language teaching. Oxford: Oxford University Press.

Larsen-Freeman, D. (1997). Chaos / complexity science and second language acquisition. Applied Linguistics, 18, 141-165.

Lave, J., \& Wenger, E. (1991). Situated learning: Legitimate peripheral participation. Cambridge: Cambridge University Press.

Muehlhaeusler, P. (1996). Linguistic ecology: Language change and linguistic imperialism in the Pacific region. London: Routledge.

Nystrand, M. (1997). Opening dialogue: Understanding the dynamics of language and learning in the English classroom. New York: Teachers College Press.

Nystrand, M., Gamoran, A., \& Carbonaro, W. (1997). Towards an ecology of learning: The case of classroom discourse and its effects on writing development in high school English and social studies. Unpublished manuscript, University of Wisconsin-Madison, National Center on English Learning and Achievement.

Oller, J. W. Jr. (1991). Language testing research: Lessons applied to LEP students and programs. Proceedings of the Second National Research Symposium on Limited English Proficient Student Issues: Focus on evaluation and measurement, 1, 43-123. Washington, DC: U.S. Department of Education, Office of Bilingual Education and Minority Languages Affairs.

Peirce, B. N. (1995). Social identity, investment, and language learning. TESOL Quarterly, 29, 9-31.

Peirce, C. S. (1955). Philosophical writings (J. Buechler, Ed.). New York: Dover Books.

Rogoff, B. (1990). Apprenticeship in thinking. New York: Oxford University Press.

van Lier, L. (1988). The classroom and the language learner: Ethnography and secondlanguage classroom research. London: Longman.

van Lier, L. (1996). Interaction in the language curriculum: Awareness, autonomy and authenticity. London: Longman.

van Lier, L. (n.d.). Computers and social interaction: Constraints and possibilities. Unpublished manuscript, Monterey Institute of International Studies, Monterey, CA.

Vygotsky, L. S. (1978). Mind in society. Cambridge: Cambridge University Press.

Wittgenstein, L. (1980). Culture and value (G. H. von Wright, Ed.). Chicago: University of Chicago Press.

\title{
Macroscopic and Microscopic Views of L2 Classrooms
}

\author{
NINA SPADA AND ROY LYSTER \\ McGill University
}

- This commentary briefly describes the development and organization of two research instruments for use in L2 classroom observation research and in L2 teacher education/reflective practice. They are contrasted in terms of the different perspectives they take on descriptions of classroom behaviours-one that provides a broader and more general view (i.e., 
macroscopic) and the other that is more specific and focussed in its description (i.e., microscopic). They are the Communicative Orientation of Language Teaching (COLT) observation scheme (Spada \& Fröhlich, 1995) and Lyster and Ranta's (1997) error treatment model. Both instruments include a set of predetermined categories to describe features of instructional input and interaction in L2 classrooms. In this way, they are similar to other research tools that are used within the interaction analysis tradition of classroom observation research. Both instruments also permit quantitative and qualitative descriptions and analyses of L2 classroom data (see Chaudron, 1988, Long, 1980; Mitchell, 1985; van Lier, 1988, for descriptions of different approaches to classroom observation research, and Spada, 1994, for a description of how COLT compares with other approaches to observation in L2 classrooms).

An observation scheme that provides a macroscopic description of L2 classrooms at the level of activity types and the verbal interactions within them is COLT. This instrument was developed in the early 1980s to describe differences in the communicative orientation of language teaching and to determine whether and how this contributes to differences in L2 learning outcomes. The categories included in COLT are, for the most part, theoretically driven. Their conceptualization was derived from a comprehensive review of theories of communicative language teaching, theories of communication, and theories of first and second language acquisition (SLA) research (see Allen, Fröhlich, \& Spada, 1984, and Fröhlich, Spada, \& Allen, 1985, for descriptions of the development and validation of the COLT scheme). COLT consists of two parts. Part A, which describes classroom practices and procedures at the level of the activity, is done in "real" time. Part B, which describes the verbal interactions between teachers and students within activities, is used in post hoc analyses that in most instances are done from transcriptions of audio-recorded data. ${ }^{1}$ Most of the 73 categories that are distributed across Parts A and B of COLT represent binary distinctions in instructional practices (e.g., student-centred vs. teacher-centred participation; reaction to form or message; genuine vs. pseudo requests; restricted vs. unrestricted language, minimal vs. sustained speech; see the Appendix, Figure 1). The COLT scheme has been used in a variety of L2 contexts to examine process and product relationships and to discover matches and mismatches between L2 program goals and practices. (See Spada, 1990a, 1990b; Spada \& Fröhlich, 1995, for a detailed description of COLT and its use in L2 classroom research.)

A research instrument that affords a more microscopic view of L2

\footnotetext{
${ }^{1}$ Only in exceptional circumstances can the verbal interaction data be coded with COLT Part B directly from the audio recordings.
} 
classrooms is Lyster and Ranta's (1997) error treatment model, which was developed in content-based L2 classrooms to describe teachers' reactions to errors and learners' immediate responses (i.e., learner uptake) to this feedback. The model is presented in the form of a flowchart (see the Appendix, Figure 2) and thus differs from COLT's grid format, which allows for concurrent coding and observation. Accordingly, the flowchart, which permits a turn-by-turn analysis of error treatment sequences in teacher-student interaction, has been used exclusively to code transcribed interactional data. In this respect, the model shares some similarities with the discourse analysis tradition in classroom observation research. Unlike COLT, the categories comprising the model are predominantly data driven. They emerged from detailed descriptions of the different types of error treatment interactions observed in immersion classrooms where L2 instruction was primarily content-based via subject-matter and language arts themes (see Lyster \& Ranta, 1997; Lyster, in press-a, in press-b, for descriptions of how these categories have been used in the analysis of classroom discourse). The development of the error treatment categories was also influenced by other feedback-on-error models used in classroom research (e.g., Doughty, 1994a, 1994b) and by two of the main features categories in COLT, Part $B$. The development and use of the categories in the error treatment sequence are a good example of the shift from macroscopic to microscopic views of language classrooms and of when and why such a shift becomes necessary.

As indicated above, there are many categories within Parts A and B of the COLT scheme. Thus, it has the capacity to capture information about a multitude of different classroom behaviours at the level of activity type and the verbal interactions that take place within them. Depending on the reasons for its use, however, it may not be (and, indeed, in most cases is not) necessary to use both parts of the scheme or all the categories within each part. For example, some users whose goals are to obtain a general picture of the communicative orientation of teaching in L2 classrooms at the level of pedagogical activities will find it adequate to use COLT, Part A. If one's research goals are to closely examine a specific feature of the linguistic interactions between students and teachers, a more focussed and detailed description is required. In such cases, one is free to either select or adapt the relevant categories from a more comprehensive scheme (e.g., features on COLT, Part B) or develop a new set of categories. Lyster and Ranta (1997) did both in designing the categories for their error treatment model. To meet their research goals, they revised the categories "reaction to form/message" and "incorporation of student utterances" in COLT, Part B. Furthermore, because this work required precise descriptions of the various types of corrective feedback and learner uptake, it was necessary to 
create additional categories that could more fully describe the linguistic behaviours of the teachers and learners in their database. In doing so, they moved from a macrolevel to a microlevel description of corrective discourse in L2 classrooms.

The COLT observation scheme and the error treatment model have been used primarily in classroom research to investigate relationships among instructional input, interaction, and SLA. However, both instruments can be (and have been) used to help teachers reflect on their teaching practices. For example, if teachers are motivated to examine how often their students are given opportunities to use the L2 in extended classroom discourse, to make genuine versus pseudorequests, or to discover whether the primary focus is on language form or meaning, they can make an audio or video recording of their own class and carry out a relatively simple analysis of their classroom behaviours using a few categories from COLT. Observing one's own class is also a useful way of discovering whether what teachers think they do is consistent with what they actually do in their teaching. For example, to reflect on their beliefs and practices concerning error treatment, teachers can begin by thinking about whether and how often they provide feedback on students' errors. They can also consider which errors they focus on (e.g., grammatical, lexical), how they do so (e.g., through explicit or implicit provision of correct forms versus signals that push learners to self-correct), and in what contexts (during or after communicative interaction). This can be followed by an audio or video recording of a lesson that teachers can then examine, using categories from the error treatment model to determine whether their beliefs are consistent with their practices (see Malamah-Thomas, 1987; Weinryb, 1992, for guidelines concerning the use of observation schemes in teacher education and reflective practice, and Mckay, 1994; Zotou, 1993, for reports of studies in which teachers' practices were examined in relation to their beliefs).

To conclude, it must be remembered that the choice of whether to use instruments such as the COLT scheme, with its wide range of categories and macroscopic perspective, or the error treatment model, with its specific focus and microscopic view, is entirely dependent on one's research goals. In some instances it may even be advantageous to use both. It is also important to keep in mind that as tools for either SLA classroom research or for teacher education and reflective practice, both instruments can be (and have been) easily adapted to serve (rather than direct) research in a variety of L2 contexts. 


\section{THE AUTHORS}

Nina Spada is Associate Professor in the Department of Second Language Education at McGill University. Her research in L2 classrooms centres on descriptions of instructional input and interaction in relationship to learning outcomes. Her current research projects are set in intensive ESL classrooms in Quebec and in English and French L2 programs for Inuit students in northern Quebec.

Roy Lyster is Associate Professor and Certificate Program Director in the Department of Second Language Education at McGill University. His research investigates the role of form-focussed instruction in content-based L2 classrooms and includes analyses of classroom interaction and the ways in which participants engage in the negotiation of form.

\section{REFERENCES}

Allen, P., Fröhlich, M., \& Spada, N. (1984). The communicative orientation of second language teaching: An observation scheme. In J. Handscombe, R. Orem, \& B. Taylor (Eds.), On TESOL '83 (pp. 231-252). Washington, DC: TESOL.

Chaudron, C. (1988). Second language classrooms. New York: Cambridge University Press.

Doughty, C. (1994a). Finetuning of feedback by competent speakers to language learners. In J. Alatis (Ed.), Georgetown University Round Table on Languages and Linguistics: Educational linguistics, crosscultural communication, and global interdependence (pp. 96-108). Washington, DC: Georgetown University Press.

Doughty, C. (1994b, March). Finetuning of L2 input: A cross linguistic study. Paper presented at the annual meeting of the American Association for Applied Linguistics, Baltimore, MD.

Fröhlich, M., Spada, N., \& Allen, P. (1985). Differences in the communicative orientation of L2 classrooms. TESOL Quarterly, 19, 27-57.

Long, M. (1980). Inside the "black box": Methodological issues in classroom research on language learning. Language Learning, 30, 1-42.

Lyster, R. (in press-a). Recasts, repetition and ambiguity in L2 classroom discourse. Studies in Second Language Acquisition.

Lyster, R. (in press-b). Relationships among error type, feedback type, and learner repair in classroom interaction. Language Learning.

Lyster, R., \& Ranta, L. (1997). Corrective feedback and learner uptake: Negotiation of form in communicative classrooms. Studies in Second Language Acquisition, 19, 37-66.

Malamah-Thomas, A. (1987). Classroom interaction. Oxford: Oxford University Press.

Mckay, P. (1994). Communicative orientation and language outcomes in Australian junior secondary foreign language classes. Unpublished doctoral dissertation, University of Queensland, Brisbane, Australia.

Mitchell, R. (1985). Process research in second language classrooms. Language Teaching, 18, 330-352.

Spada, N. (1990a). A look at the research process in classroom observation: A case study. In C. Brumfit \& R. Mitchell (Eds.), ELT Documents: Research in the language classroom (pp. 81-93). London: Modern English Publications/British Council.

Spada, N. (1990b). Observing classroom behaviours and learning outcomes in different second language programs. In J. C. Richards \& D. Nunan (Eds.), Second language teacher education: Content and process (pp. 293-312). New York: Cambridge University Press. 
Spada, N. (1994). Classroom interaction analysis. In A. Cumming (Ed.), Alternatives in TESOL research: Descriptive, interpretive and ideological orientations. TESOL Quarterly, 28, 685-688.

Spada, N., \& Fröhlich, M. (1995). Communicative Orientation of Language Teaching (COLT) observation scheme: Coding conventions and applications. Sydney, Australia: Macquarie University, National Centre for English Language Teaching and Research.

van Lier, L. (1988). The classroom and the language learner. London: Longman.

Weinryb, R. (1992). Classroom observation tasks: A resource book for language teachers and trainers. Cambridge: Cambridge University Press.

Zotou, V. (1993). Effective foreign language teaching: A Greek case study. Unpublished doctoral dissertation, University of South Hampton, England. 


\section{APPENDIX}

\section{Research Instruments for Classroom Observation}

FIGURE 1

Communicative Orientation of Language Teaching (COLT) Observation Scheme

COLT part A

Communicative Orientation of Language Teaching Observation Scheme

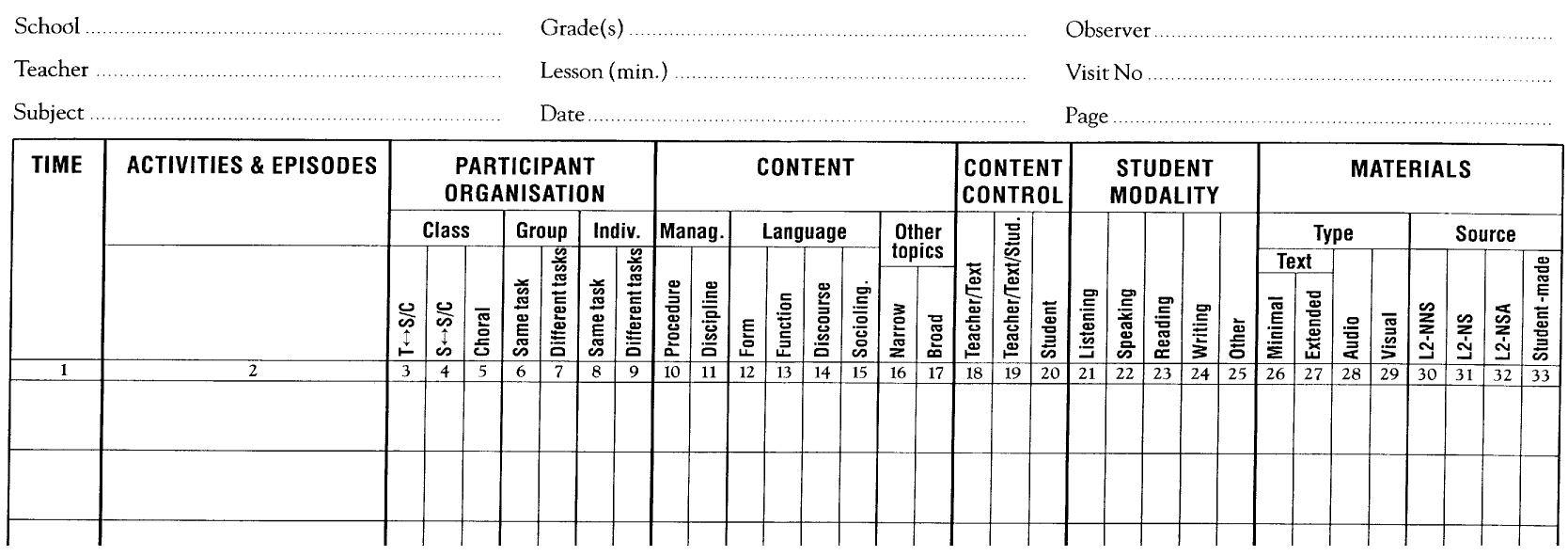




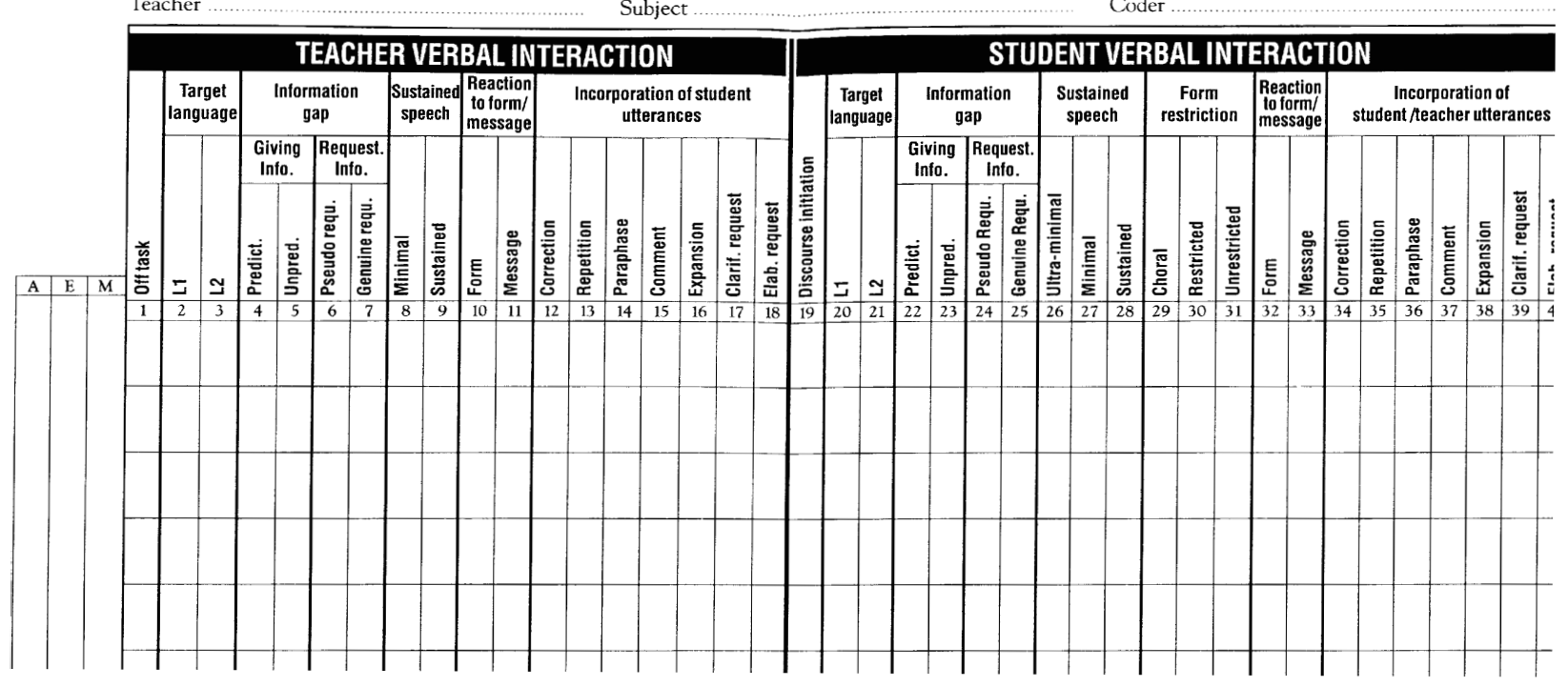

Note. From Communicative Orientation of Language Teaching (COLT) observation scheme: Coding Conventions and Applications (pp. 13, 20), by N. Spada and M. Fröhlich, 1995, Sydney, Australia: Macquarie University, National Centre for English Language Teaching and Research. Copyright 1995 by the National Centre for English Language Teaching and Research, Macquarie University, Sydney, New South Wales, 2109, Australia. Reprinted with permission. 
FIGURE 2

Error Treatment Sequence

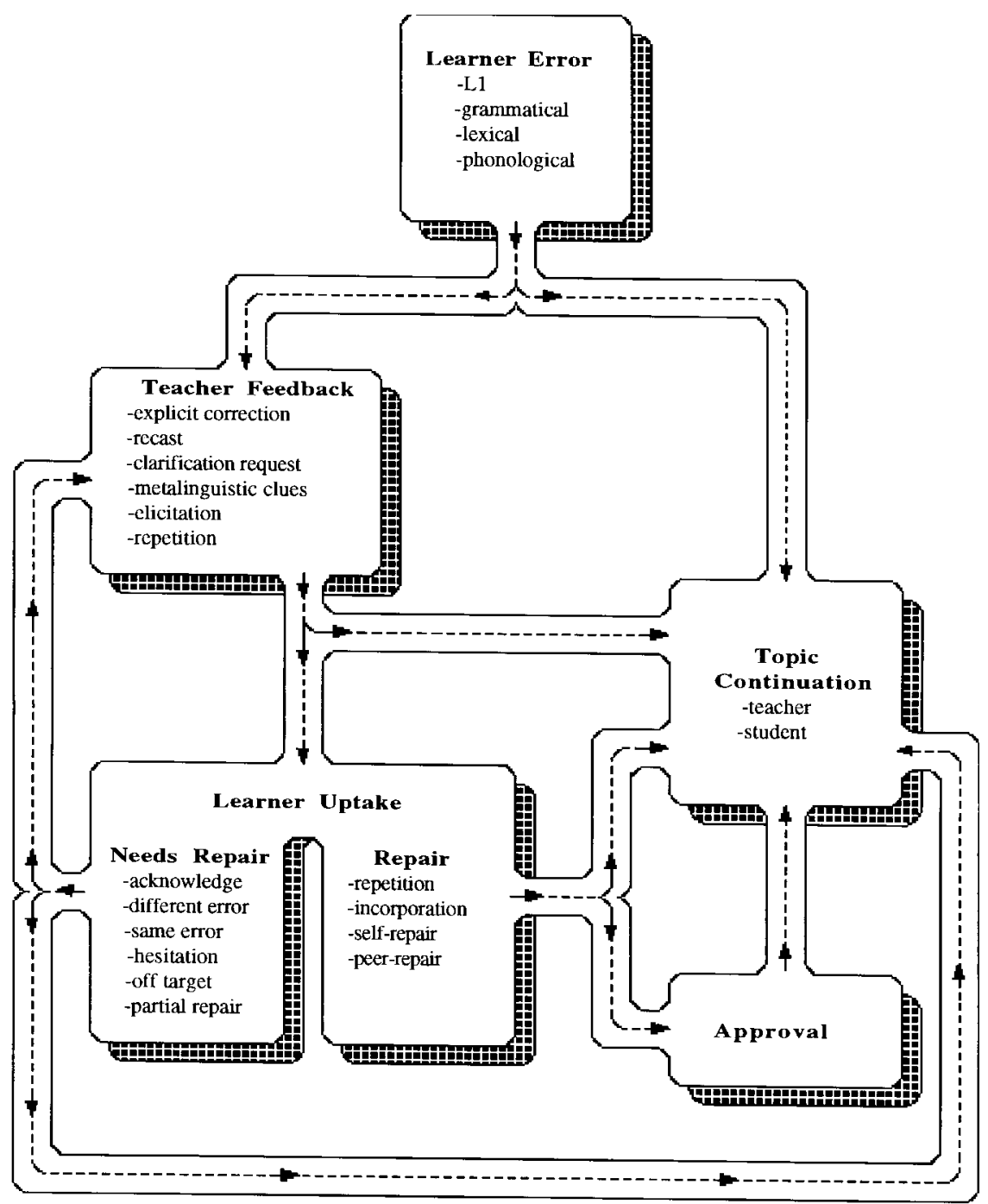

Note. Adapted from "Corrective Feedback and Learner Uptake: Negotiation of Form in Communicative Classrooms," by R. Lyster and L. Ranta, 1997, Studies in Second Language Acquisition, 19, 44. 